\title{
Gestational diabetes mellitus - need for universal screening - a clinical study in a tertiary care centre
}

\author{
Kondapuram Veena*, Srilakshmi Ambarkar
}

Department of Obstetrics and Gynecology, Kurnool Medical College, Kurnool, Andhra Pradesh, India

Received: 08 March 2021

Revised: 11 April 2021

Accepted: 12 April 2021

\section{*Correspondence:}

Dr. Kondapuram Veena,

E-mail: veenakondapuram@gmail.com

Copyright: (c) the author(s), publisher and licensee Medip Academy. This is an open-access article distributed under the terms of the Creative Commons Attribution Non-Commercial License, which permits unrestricted non-commercial use, distribution, and reproduction in any medium, provided the original work is properly cited.

\section{ABSTRACT}

Background: To study the prevalence of gestational diabetes mellitus among antenatal mothers and to assess the importance of universal screening to detect gestational diabetes mellitus (GDM).

Methods: A total of 300 antenatal women irrespective of gestational age were screened for GDM at their antenatal visit during the period of January 2020 to June 2020. All women were screened with $75 \mathrm{gm}$ oral glucose load irrespective of last meal followed by blood glucose estimation by glucose oxidase peroxidase method 2 hours following glucose load. A cut-off of $140 \mathrm{mg} / \mathrm{dl}$ or more were labelled as gestational diabetes mellitus as per DIPSI guidelines.

Results: Out of 300 antenatal women tested, 24 women (8\%) were positive for gestational diabetes mellitus. During the first, second and third trimesters $12.5 \%, 33.33 \%$ and $54.17 \%$ were diagnosed with gestational diabetes mellitus respectively. The number of gestational diabetes mellitus patients for the age groups $\leq 20$ years, 21-25 years, 26-30 years and $>30$ years are $2(8.33 \%), 3(12.5 \%), 8(33.33 \%)$ and $11(45.83 \%)$ respectively. The number of pregnant women tested positive for gestational diabetes mellitus with BMI $\leq 18.5,18.6-24.9,25-29.9$ and 30-35 are $2(8.33 \%)$, $4(16.67 \%), 8(33.33 \%)$ and $10(41.67 \%)$ respectively.

Conclusions: Prevalence of GDM in our study is $8 \%$. About $29.16 \%$ of GDM did not have any risk factors. This emphasizes the importance of universal screening for GDM of all pregnant women irrespective of gestational age. There is an increased association of GDM with age, BMI, family history and parity according to our study.

Keywords: DIPSI, Gestational diabetes mellitus, Universal screening

\section{INTRODUCTION}

Gestational diabetes mellitus is defined as glucose intolerance of varying severity with onset or first recognition during pregnancy. Prevalence of GDM is increasing globally especially in Asian women. ${ }^{1}$ GDM is associated with adverse maternal and perinatal outcomes that include preeclampsia, polyhydramnios, increased operative intervention, macrosomia, congenital anomalies, Intra uterine growth restriction, Intra uterine death and subsequent childhood and adolescent obesity. Women with history of GDM are at increased risk of future diabetes predominantly type 2 diabetes. Early imprinting (i.e. in intrauterine life) is believed to have effects later in life, so their children are at increased risk of childhood obesity and diabetes in adulthood. So two generations are at risk. $^{2}$ Therefore it is important to diagnose early and treat promptly to prevent complications. GDM has become public health priority as stillbirth rate is high in India and one of the causes is GDM. ${ }^{3}$ High prevalence of diabetes and genetic predisposition to metabolic syndrome exists among Asians particularly among Indian women as they are at 11 fold increased risk of glucose intolerance compared to 
Caucasians. ${ }^{4}$ So this predisposes Indian women to develop GDM and its complications in all trimesters of pregnancy. Prevalence of GDM in India varies from 3.8 to $21 \%$ in different parts of the country, depending on geographical locations and diagnostic methods used..$^{5-7}$

So there is a need for cost effective, simple universal screening and diagnostic method. This initiated us to conduct a study on universal screening for GDM irrespective of gestational age by DIPSI method.

\section{METHODS}

This was a prospective study conducted in the department of OBG at Kurnool medical college, Kurnool from January 2020 to June 2020.

\section{Inclusion criteria}

All antenatal women attending antenatal clinic for the first time irrespective of gestational age.

\section{Exclusion criteria}

Women already diagnosed with overt diabetes mellitus, women who had not given written consent for the study

A total of 300 antenatal women attending antenatal clinic for the first time for registration and those coming for follow up visit, irrespective of their gestational age were selected for the study. The details of age, height, weight, occupation, family history of diabetes mellitus present obstetric history were obtained. Also details regarding past obstetric history such as history of GDM, stillbirth, IUD, polyhydramnios, giving birth to macrosomic baby, anomalous baby were obtained. BMI of all subjects were obtained using Quetelet Index. Blood pressure of all women were recorded. Features such as acanthosis nigricans were observed for. All the women were then given $75 \mathrm{gm}$ oral glucose load irrespective of last meal followed by blood glucose estimation by glucose oxidase peroxidase method two hours following glucose load. A cutoff of $140 \mathrm{mg} / \mathrm{dl}$ or more were labelled as GDM as per DIPSI guidelines.

\section{Statistical analysis}

After collecting data, statistical analysis was done by using Descriptive statistics - Mean, Standard deviation, and the inferential statistics

\section{RESULTS}

Majority of the pregnant women who participated in the study were in the age group of $21-25$ years $(40.67 \%)$. The mean age of the study population was $24.85 \pm 4.12$. The average BMI was 23.82 \pm 4.33 . Out of 300 pregnant women, 24 were tested positive for GDM. So the prevalence in our study was $8 \%$. Among the 24 GDM patients, 7 members $(29.16 \%)$ did not have any risk factors.

Table 1: Association of age with GDM.

\begin{tabular}{|lll|}
\hline Age in years & $\begin{array}{l}\text { Number of GDM } \\
\text { patients }\end{array}$ & Percentage \\
\hline$\leq \mathbf{2 0}$ & 2 & 8.33 \\
\hline $\mathbf{2 1 - 2 5}$ & 3 & 12.50 \\
\hline $\mathbf{2 6 - 3 0}$ & 8 & 33.33 \\
\hline $\mathbf{> 3 0}$ & 11 & 45.83 \\
\hline
\end{tabular}

Table 2: Association of BMI with GDM.

\begin{tabular}{|lll|}
\hline BMI & $\begin{array}{l}\text { Number of GDM } \\
\text { patients }\end{array}$ & Percentage \\
\hline $\mathbf{1 8 . 5}$ & 2 & 8.33 \\
\hline $\mathbf{1 8 . 6 - 2 4 . 9}$ & 4 & 16.67 \\
\hline $\mathbf{2 5 - 2 9 . 9}$ & 8 & 33.33 \\
\hline $\mathbf{3 0 - 3 5}$ & 10 & 41.67 \\
\hline
\end{tabular}

Table 3: Incidence of GDM in different trimesters.

\begin{tabular}{|lll|}
\hline $\begin{array}{l}\text { Trimester } \\
\text { number }\end{array}$ & $\begin{array}{l}\text { Number of GDM } \\
\text { patients }\end{array}$ & Percentage \\
\hline $\mathbf{1}^{\text {st }}$ trimester & 3 & 12.50 \\
\hline $\mathbf{2}^{\text {nd }}$ trimester & 8 & 33.33 \\
\hline $\mathbf{3}^{\text {rd }}$ trimester & 13 & 54.17 \\
\hline
\end{tabular}

Table 4: Association of GDM and other variables.

\begin{tabular}{|lll|}
\hline Variable & Number of GDM patients & Percentage \\
\hline Obesity & 18 & 58.33 \\
\hline History of GDM in previous pregnancy & 3 & 12.50 \\
\hline history of macrosomic baby & 5 & 20.83 \\
\hline history of anomalous baby & 0 & 0.00 \\
\hline IUD & 2 & 8.33 \\
\hline family history & 12 & 50.00 \\
\hline infertility & 4 & 16.67 \\
\hline Hypothyroidism & 6 & 25.00 \\
\hline history of miscarriage & 7 & 29.17 \\
\hline Preeclampsia & 5 & 20.83 \\
\hline
\end{tabular}


The number of GDM patients for the age groups $\leq 20$ years, 21-25 years, 26-30 years and $>30$ years are 2 $(8.33 \%), 3(12.5 \%), 8(33.33 \%)$ and $11(45.83 \%)$ respectively (table 1). The number of GDM pregnant women tested positive for GDM for BMI $\leq 18.5$ are 2 $(8.33 \%)$ (Table 2$)$.

Similarly for the BMI ranges between 18.6-24.9, 25-29.9 and $30-35$, the number of GDM patients were 4 $(16.67 \%), 8(33.33 \%)$ and $10(41.67 \%)$ respectively (Table 2). The number of GDM cases during first, second, and third trimesters were 3(12.5\%), $8(33.33 \%)$ and $13(54.17 \%)$ respectively (Table 3$)$.

\section{DISCUSSION}

Diabetes mellitus is an epidemically explosive problem which is increasing at an unstoppable pace. India has the highest number of type 2 diabetes patients and has been called the diabetic capital of the world with more than 43 million diabetics in the country. ${ }^{8}$ And lot of these are women in child bearing age group. Further early screening for glucose intolerance and appropriate measures could avoid some diabetic related complications in women with GDM and their new born. The prevalence of GDM in our study was $8 \%$. In our study, prevalence of GDM increased significantly with advanced maternal age. A similar association of GDM with advanced maternal age has been reported by seshaiah et al. ${ }^{4}$

Obesity is an important modifiable risk factor in development of GDM. In our study GDM was found to be significantly higher $(75 \%)$ in women with higher BMI. A similar association has been found by Jang et al. ${ }^{9}$ A significantly higher percentage of women with GDM has positive family history of diabetes mellitus $(50 \%)$ in our study. Family history of diabetes mellitus has been reported to be associated with higher chances of developing GDM by kim et al. ${ }^{10}$

In our study $12.5 \%$ of patients had history of GDM in previous pregnancy and $20.83 \%$ had history of macrosomic baby in previous pregnancy. Also a significantly higher percentage of women with GDM has associated hypothyroidism $(25 \%)$ and preeclampsia $(20.83 \%)$. Incidence of GDM in first trimester is $12.5 \%$, second trimester is $33.33 \%$ and third trimester is $54.17 \%$. This high incidence noted in third trimester was because ours being a tertiary care centre, most of the antenatal women will get registered at nearby PHC for their initial antenatal check-ups and they visit tertiary care centre in third trimester for institutional delivery.

There is increased prevalence of GDM in women with advanced age, obesity, family history of diabetes mellitus. About $29.16 \%$ of GDM patients did not have any risk factors.
This emphasizes the importance of universal screening for GDM of all pregnant women irrespective of gestational age. It has been observed that BMI is a risk factor for GDM which is modifiable. So women in reproductive age group who are at risk of diabetes should undergo pre-conceptional counselling and proper life style modifications before planning pregnancy so as to prevent adverse maternal and foetal outcomes. Limitations of study were other comorbid factors were not evaluated in detail.

\section{CONCLUSION}

Timely diagnosis and intervention is of great help in improving both short and long term health benefits of mother and baby. DIPSI test is a simple, economical and less cumbersome method for detecting GDM. Universal screening for GDM irrespective of trimesters is important as $29.16 \%$ of GDM patients did not have any risk factors.

Funding: No funding sources

Conflict of interest: None declared

Ethical approval: The study was approved by the Institutional Ethics Committee

\section{REFERENCES}

1. Ferrara A. Increasing prevalence of gestational diabetes mellitus: a public health perspective. Diab care. 2007;30(2):S141-6.

2. Girling J, Dornhorst A. Pregnancy and diabetes mellitus. In John C Pick Up, Gareth Williams (eds) Textbook of Diabetes. $3^{\text {rd }}$ edition. Blackwell publishing company. 2003.

3. Pattinson R, Kerber K, Buchmann E, Friberg IK, Belizan M, Lansky S, et al. Stillbirths: how can health systems deliver for mothers and babies? Lancet. 2011;377(9777):1610-23.

4. Seshaiah V, Balaji V, Balaj MS, Sekhar A, Sanjeevi $\mathrm{CB}$, Green A. One step procedure for screening and diagnosis of gestational diabetes mellitus. J Obset Gynecol Ind. 2005;55:525-9.

5. Seshiah V, Balaij V, Balaji SM, Panneerselvam A, Kapur A. Pregnancy and Diabetes Scenario around the World: India. Int $\mathbf{J}$ Gynaec Obstet. 2009; 104:S35-8.

6. Seshiah V, Balaji V, Balaji MS, Panneerselvam A, Arthi T, Thamizharasi $M$ et al. Prevalence of GDM in South India (Tamil Nadu)-a Community based study. J Assoc Phys Ind. 2008;56:329-33.

7. Zargar AH, Sheikh MI, Bashir MI, Masoodi SR, Laway BA, Wani AI et al. Prevalence of gestational diabetes mellitus in Kashmiri women from the Indian subcontinent. Diabetes Res Clin Pract. 2004;66(2):139-45.

8. Metzger BE, Gabbe SG, Persson B, et al. International association of diabetes and pregnancy study group recommendations on the diagnosis and classification of hyperglycemia in pregnancy. Diabetes Care. 2010;33(3):675-82. 
9. Jang HC, Cho NH, Jung KB, Oh KS, Dooley SL, Metzger BE, Screenig for gestational diabetes mellitus in Korea. Int J Gynecol Obstet. 1995;51:1122

10. Kim C, Lui T, Val dez R, Beckles GL, Diabetes in first degree relatives of pregnant woman affect the likelihood of her developing gestational diabetes or non-gestational diabetes? Am J Obstet Gynec. 2009;201(6):576-e1.

Cite this article as: Veena $\mathrm{K}$, Ambarkar S.

Gestational diabetes mellitus - need for universal screening - a clinical study in a tertiary care centre. Int J Reprod Contracept Obstet Gynecol

2021;10:1973-6. 